
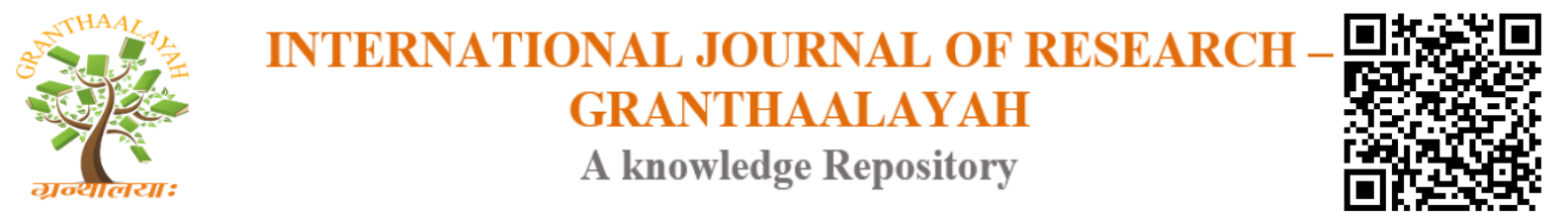

Management

\title{
IMPACT OF ACCOUNTING INFORMATION SYSTEM IN REDUCING COSTS IN JORDANIAN BANKS
}

\author{
Dr. Aisar Ayed Nahar Albashabsheh', Dr. Modafar Nayel Alhroob², Dr. Belal Eid Irbihat ${ }^{3}$, \\ Dr. Sarfaraz Javed ${ }^{4}$ \\ 1, 2,3 Department of Commerce, AMU, Aligarh, India \\ ${ }^{4}$ Assistant Professor, Department of Business Studies, Jahangirabad Institute of Technology, \\ Barabanki, India
}

\begin{abstract}
This study is an attempt to analyses the impact of accounting information system in reducing costs in Jordanian banks. This study consist primary and secondary method of collecting and analysis data. This study focus on the two main objectives and three hypothesis developed on the after the in-depth study of relevant literature. The need for accounting systems increases in its regard as a mean which derives its importance and necessity from its level of contribution in improving the value chain of business organizations, it helps in providing the needs from various resources and optimally allocating them under conditions of risk and uncertainty surrounding the business environment. The accounting system is considered as one of the most important information systems that contribute to the rationalization and support of economic decisions which affect the resources and wealth of communities and hence on the welfare of individuals. The accounting system also involves a close relationship with relevant administrative process which involves several tasks and functions; thus, contributing in the improvement of the value chain of business organizations and increasing the level of goal achieving performance. The accounting systems are also used as the basis of evaluating the efforts made in various administrative levels to accomplish tasks and achieve goals.
\end{abstract}

Keywords: Impact; Reducing Costs; Information; Accounting.

Cite This Article: Dr. Aisar Ayed Nahar Albashabsheh, Dr. Modafar Nayel Alhroob, Dr. Belal Eid Irbihat, and Dr. Sarfaraz Javed. (2018). "IMPACT OF ACCOUNTING INFORMATION SYSTEM IN REDUCING COSTS IN JORDANIAN BANKS." International Journal of Research - Granthaalayah, 6(7), 210-215. 10.29121/granthaalayah.v6.i7.2018.1300.

\section{Introduction}

In managing an organization and implementing an internal control system, the role of accounting information system is very crucial (Nicoloaou, 2000). The qualitative characteristic of any Accounting Information System (AIS) can be maintained if there is a sound internal control system. In any AIS environment, the qualities of internal controls adaptation affect operations and 
management and in turn influence internal control system. Internal control is run to ensure the achievement of operational goals and performance.

Wilkinson et al (2000) noted that the main function of accounting information system is to assign quantitative value of the past, present, and future economics events. AIS through its computerized accounting system produces the financial statement namely, income statement, the balance sheet, and cash flow statement. Normally, the system will process the data and transform them into accounting information during input, processing and output stages that can be used by a variety of users like the internal and external users. Therefore, if companies are able to adjust their computerized techniques of internal control mechanism according to AIS, they will be able to ensure the reliability of financial information processing and boost the control measures of effectiveness of the financial information reliability. When the controls are used properly there will be better operating effectiveness and efficiency which will result in better financial information reliability. Managers at various levels need AIS to make decisions in internal controls (Hoitash and Bedard 2009).

Accounting in a commercial bank represents one of the most important pillars in the business organization and operation of the bank, if not the most important of all, since it provides a basic foundation of information for planning, surveillance, monitoring and evaluating performance and decision-making. Banking activity is sensitive to all variables and events that take place in both the internal and external bank's work environment at the local and global level. Therefore banks need an integrated information department that can be relied upon to provide a minimum level of security, trust, objectivity, and assurance for all relevant parties (Mohammad, 1993). Banks in the Middle East in general and Jordan in particular, are interested in seeking out and taking advantage of the real opportunities presented by widespread economic and social transformations. Such opportunities are afforded by the framework of AIS inherited powers, and in light of the development and rise in the level of productivity to create better economic growth. Banks are also interested in providing new careers and access to the building environment, openly and competitively, and to access higher levels of innovation. In particular, banks are directly based on IS and the private accounting sector, including work and activities; hence the importance of AIS in business practice of banks. The continuous development of information technology in the modern word affects the performance of Accounting Information Systems (AIS) in Jordanian business organizations, including commercial banks, in many respects, including: its objectives, strategies, nature of work and instruments that achieve its objectives. The present study examines the impact of Accounting Information System (AIS) in reducing costs in Jordanian banks.

\section{Objectives of the Study}

The primary objective of this study is to examine the impact of Accounting Information System (AIS) in reducing costs in Jordanian banks. The secondary objectives are as follows:

1) To examine the impact of Accounting Information System on managing accounting procedures in banks in Jordan.

2) To examine the impact of Accounting Information System on performance of banks in Jordan. 


\section{Research Hypotheses}

$\mathrm{H}_{01}$ : Accounting Information System has no significant impact on cost reduction by banks in Jordan.

$\mathrm{H}_{02}$ : Accounting procedures do not significantly influence Accounting Information System in Jordan banks.

$\mathrm{H}_{03}$ : Accounting Information System has no significant impact on bank performance in Jordan.

\section{Literature Review}

Haddad and Atmeh (2007) studied the factors relating to information technology and environment affecting the role of accounting information system in decision making strategy in Jordanian industrial companies. The researchers made use of 114 questionnaires which were distributed to key officers in the Jordanian industrial companies e.g. the CEO, Financial managers, production and marketing managers. Their findings based on their analysis showed that there is a positive relationship between information technology, environment, and accounting information system but did not find a relationship between accounting information and strategic decision making.

Thaer, Laith and Anyam (2014) explored the research study on the factors affecting the effectiveness of accounting information system in Jordanian private higher education. Criterion validity analysis was conducted by using the dependable variable (human resource efficiency, software and hardware efficiency, database efficiency) and the undependable variable Accounting Information Systems efficiency. Pearson correlation was used to quantify the strength of the relationship between the two variables. Their results showed that the human resources, hardware, software and data bases have a positive relationship with the efficiency of AIS.

Marshal and JohnSteinbart (2015) in their study alleged that developing an internal control system requires a thorough understanding of information technology (IT) capabilities and risk s as well as how to use IT to achieve an organizational control objectives. Accountant and systems developers help management achieve their control objectives by (1) designing effective control systems that take a proactive approach to eliminating systems and detect, correct, and recover from threats when they occur .(2) making it easier to build controls into systems at the initial design stage than to add them after the facts. Wilkinson et al (2000) noted that an effective accounting information system performs several key functions such as data collection, data maintenance, data information accounting systems and knowledge management, data control (including security) and information generation.

Perez, Raquel, and Clara (2011) explored the impact of accounting information system (AIS) on performance measures, with empirical evidence in Spanish small medium enterprises (SMEs). The research was carried out based on a survey to ascertain the extent to which development and implementation of accounting information systems had taken place in the small and medium- sized enterprises and afterward an analysis was made on the extent of the impact of the introduction of accounting information system on the improvement of outcome indictors and productivity. Following the stage of research an ANOVA analysis was made to compare measures among the four SMEs samples and results. The result shows that there is a positive relationship between the SMEs that use AIS for fiscal and bank management and better performance measures. 


\section{Methods}

The data for this study is the secondary data on financial data available on Amman Stock Exchange from 2013 to 2016. The study employed correlation and descriptive statistics in analyzing the data. Pearson correlation was used to test the three hypotheses and SPSS version 17 was used to perform Pearson Product Moment Correlation.

Table 1: Descriptive Statistics of Variables

\begin{tabular}{|l|l|l|l|l|l|}
\hline Variables & $\mathbf{N}$ & Minimum & Maximum & Mean & Std. Deviation \\
\hline logFinRev & 4 & 5.57 & 5.62 & 5.6024 & .02179 \\
\hline logProf & 4 & 6.15 & 6.51 & 6.3150 & .18068 \\
\hline logNetIncome & 4 & 7.67 & 7.78 & 7.7082 & .05014 \\
\hline logIncomeTax & 4 & 7.29 & 7.52 & 7.3888 & .10772 \\
\hline logTotalExpenses & 4 & 7.82 & 7.93 & 7.8666 & .05034 \\
\hline logEmployeeExpenses & 4 & 7.59 & 7.65 & 7.6108 & .02897 \\
\hline logCashbalanceBegin & 4 & 8.88 & 9.09 & 9.0130 & .09515 \\
\hline logCashbalanceEnding & 4 & 9.02 & 9.12 & 9.0744 & .04623 \\
\hline logTotalIncome & 4 & 8.13 & 8.25 & 8.1743 & .05949 \\
\hline Expenses & 4 & 7.82 & 7.93 & 7.87 & .05034 \\
\hline
\end{tabular}

Table 1 shows that $\log$ Cash balance Ending has the highest mean $(M=9.07, S D=.046)$, followed by $\log$ Cash Balance Begin with $(M=9.01, S D=.095)$. Also, log Total Income has mean with $(M=8.17, S D=.059)$, Expenses has a mean with $(M=7.87, S D=.0503)$, log Net Income has mean with $(M=7.708, S D=.0501)$.

Table 2: Impact of AIS on cost reduction

\begin{tabular}{|l|l|l|l|}
\hline Variables & logExpenses & AIS & logFinReve \\
\hline logExpenses & 1 & & \\
\hline AIS & $-.982^{*}$ & 1 & \\
\hline logFinRev & 914 & $.974 *$ & 1 \\
\hline
\end{tabular}

Table 2 shows the correlation between Accounting Information System and expenditure. There was a negative correlation between AIS and Expenses $(r=-.982, \mathrm{p}<.05)$ and no correlation between AIS and Financial Revenue. This implies that better application of Accounting Information System reduces cost.

Table 3: Impact of AIS on bank performance

\begin{tabular}{|l|l|l|l|l|l|l|}
\hline Variables & $\mathbf{1}$ & $\mathbf{2}$ & $\mathbf{3}$ & $\mathbf{4}$ & $\mathbf{5}$ & $\mathbf{6}$ \\
\hline logProf & - & & & & & \\
\hline AIS & $.674^{*}$ & - & & & & \\
\hline logNetIncome & .395 & -.541 & - & & & \\
\hline $\log$ TotalIncome & $.989^{*}$ & .447 & .481 & - & & \\
\hline 5. logCashbalanceBegin & .708 & $.974^{*}$ & -.342 & .655 & - & \\
\hline 6.logCashbalanceEnding & .660 & .600 & .104 & .715 & .591 & - \\
\hline
\end{tabular}

* Correlation is significant at the 0.05 level (2-tailed).

** Correlation is significant at the 0.01 level (2-tailed). 
Table 3 shows the correlation between Accounting Information System and Bank Performance. There was a positive correlation between Total Profit and AIS $(r=.674, p<.05)$. There was also a significant positive correlation between Total Profit and Total Income ( $r=.989, \mathrm{p}<.05)$. This result implies that AIS has positive impact on the Total Profits of banks in Jordan which in turn has positive impact on bank performance.

Table 4: Impact of Accounting Procedures on AIS

\begin{tabular}{|l|l|l|l|l|l|}
\hline Variables & $\mathbf{1}$ & $\mathbf{2}$ & $\mathbf{3}$ & $\mathbf{4}$ & $\mathbf{5}$ \\
\hline AIS & - & & & & \\
\hline logCashBalanceBegin & .500 & - & & & \\
\hline logCashbalanceEnding & $.702^{*}$ & .731 & - & & \\
\hline logFinRev & $.295^{*}$ & $.974^{*}$ & .600 & - & \\
\hline \multicolumn{1}{|c|}{ 5. logIncomeTax } & .913 & .693 & .591 & .544 & - \\
\hline
\end{tabular}

* Correlation is significant at the 0.05 level (2-tailed).

** Correlation is significant at the 0.01 level (2-tailed).

Table 4 shows the impact of Accounting procedures on Accounting Information System (AIS). There was a positive correlation between AIS and $\operatorname{logFinRev}$ (Financial Revenue) $(r=.275, \mathrm{p}<.05)$ and a positive correlation between AIS and Cash balance ending $(r=.702, p<.05)$. There was no correlation between AIS and Cash balance beginning and Income Tax.

\section{Discussion and Conclusion}

This study examines the impact of accounting information system in reducing costs in Jordanian banks. The findings of this study shows that there was a negative correlation between AIS and Expenses which implies that application of Accounting Information System minimizes expenses of banks in Jordan. In addition, there was a positive correlation between Total Profit and AIS while there was also a significant positive correlation between Total Profit and Total Income. This finding reveals that AIS has positive impact on the Total Profits of banks in Jordan which in turn has positive impact on bank performance. Furthermore, there was a positive correlation between AIS and Financial Revenue and Cash Balance Ending. These findings are in support of the study of Perez, Raquel, and Clara (2011) who shows that there is a positive relationship between the SMEs that use AIS for fiscal and bank management and better performance measures. This clearly shows the importance and relevance of Accounting Information System in managing accounting practices of banks in Jordan. Therefore, if companies and banks are able to adjust their computerized techniques of internal control mechanism according to AIS, they will be able to ensure the reliability of financial information processing and boost the control measures of effectiveness of the financial information reliability.

\section{References}

[1] Haddad, \& Atmeh. (2009). Accounting information system (1st Edition). Amman: Al Mareekh.

[2] Marshal, B.R. \& JohnSteinbart, R. (2015): Accounting Information Systems. Thirteen Edition. Pearson Education Limited. Pp 214-234.

[3] Mohammad, M.A. (1993). Accounting Information System in the Commercial Banks. $2^{\text {nd }}$ edition, Cairo, Egypt: Ain Shams Library. pp. 42-44. 
[4] Nicolaou, A. (2000). A contingency Model of perceived effectiveness in Accounting Information System: Organasational Cordination and control effect "International journal of accounting information systems Vol.1pp.91-105

[5] Pérez, R., Urquía, E., \& Muñoz, C. (2010). Information technology implementation: evidence in Spanish SMEs. International Journal of Accounting \& Information Management, 18(1), 39-57.

[6] Wilkinson, J.W., Cerullo, M.J., Raval,V.and Wong-On-Wing, B.(2000).Accounting Information Systems: Essential concepts and Applications. Network: John Wiley and sons.

*Corresponding author.

E-mail address: albertphd1986@gmail.com 